\title{
Economic Booms, Trade Deficits, and Economic Policy*
}

\author{
Francisco Alcalá and Diego Peñarrubia ${ }^{\dagger}$ \\ Universidad de Murcia
}

July, 2000

(First version: June 1999)

\begin{abstract}
Many economic booms have been accompanied by real exchange rate appreciations, large trade deficits -which have sometimes persisted after the return to the initial exchange rate parity- and a deteriorating traded sector. Those circumstances have typically raised the question of the desirability of some stabilization policy. We show that the dynamics induced by an expected productivity shock in an economy where the capital stock is non-mobile across sectors, match those circumstances. Furthermore, we obtain that credit market imperfections tend to exacerbate trade deficits, and to cause an inefficient capacity reduction in the traded sector. Some stabilization policies are explored. (JEL Classification: F41, F43, E62)

Keywords: new open economy macroeconomics, non-traded goods, financial accelerator, trade deficit persistence.
\end{abstract}

\footnotetext{
${ }^{*}$ We have benefited from comments by A. Cabrales and A. Ciccone, and by participants at the European Economic Association Congress in Berlin and at seminars at Universidad de Murcia and Universitat Pompeu Fabra. We also thank the hospitality of the Universitat Pompeu Fabra where this paper was completed. Financial support by the Spanish Ministry of Education, DGESIC (PB97-1057), is gratefully acknowledged.

$\dagger$ Address: Facultad de Economía y Empresa. Universidad de Murcia. Campus de Espinardo. 30100. Espinardo (Murcia). Spain. Fax: 34-968-363758. E-mails: falcala@um.es and diegope@um.es
} 


\section{Introduction}

Many economic booms have been accompanied by real exchange rate appreciations, large trade deficits and a deteriorating traded sector. The USA economy during the mid-eighties is a well-known case. Similarly well-known is the case of the Asian new industrialized countries where -besides their specific financial problems- sharp economic growth led to great real exchange appreciations and accelerating current account deficits before the 1997 crash. $^{1}$ But many other countries have experienced similar situations. In Europe for instance, the positive economic prospects created in Spain by the entry into the European Community in the mid-eighties, brought about an intense period of economic boom. The burst in aggregate demand increased the relative price of nontraded goods -implying an important real exchange rate appreciation- and prompted a large and persistent trade deficit. Many firms in the traded sector suffered losses and financial difficulties, and were unable to survive the boom. When the boom was over, important parts of the traded sector -especially that consisting of small and medium sized firms- had disappeared. ${ }^{2}$

These circumstances have typically raised questions about the optimallity of the path being followed, and about the convenience of some stabilization policy. Should we care about large and persistent current account deficits? Are there any grounds to suspect that the breakdown of a significant part of the traded sector

\footnotetext{
${ }^{1}$ The average ratio of current account deficit to GDP between 1994 to 1996 in Indonesia, Korea, and Thailand was between $2.4 \%$ and $7.2 \%$; and their average GDP growth was in all three cases above $7.5 \%$. On the other hand,the dramatic devaluations of 1997 leave little doubt that a somehow high real exchange rate was a third element characterizing the years before the crash.

${ }^{2}$ The boom that followed Spanish entry into the EEC lasted from 1987 to 1991, and resulted in an average economic growth of $4.25 \%$. Real exchange rate with respect to industrialized countries' currencies appreciated $21.8 \%$ within this same period. Trade deficit moved on average above a $2.7 \%$ of GDP between 1988 and 1992, and reached a peak of 3,9\% the year the boom ended: 1992. With respect to the number of bankruptcies, the are not data available per industry. But regional data provide some interesting information. The share of the five most export oriented Spanish regions in the total number of bankruptcies in the Spanish economy was 13.8\% higher between 1987 and 1991, than in the five previous years. Then, in the following five years, 1992-1996, this share was 17.3\% lower than in 1987-1991. On the other side, the bankruptcy share of the five least export oriented Spanish regions was 22.3\% lower in 1987-1991 than in 1982-1986; and 13.2\% higher in 1992-1996 than in 1987-1991. Fernández de Córdoba and Kehoe (2000) offer an analysis of this case taking an approach quite different from the one in this paper.
} 
in the excitement of a boom is not always a positive ingredient of an optimal equilibrium path?

Clearly, the potential reason to be concerned by these phenomena would be the existence of market failures. The difficulty to interpreting them, and to eventually suggest policy responses, arises from the relative lack of suitable theory. Though growing at an increasing path, the analysis of the dynamics of open economies under market imperfections, in the framework of the intertemporal approach, is still under development. ${ }^{3}$ This is for instance the approach taken by the so-called "New Open Economy Macroeconomics" which, following Obstfeld and Rogoff's (1995) work among others, has focused on the role of imperfect competition and price stickiness as the source for potential inefficiencies. Another branch of literature within the few existing examples exploring the consequences of market failures for the dynamics of open economies, is that on the "Dutch disease". This literature has taken into account the existence of dynamic economies of scale to analyze the consequences that the discovery of new natural resources may have for a country's industry. ${ }^{4}$ In this paper we consider the impact of a different market failure, namely the imperfect working of credit markets due to informational asymmetries, which may play an important role in the dynamics of open economies experiencing temporary intense processes of growth such as those cited above.

The macroeconomic consequences of credit market imperfections in closed economies have received much attention in recent times. ${ }^{5}$ In general, it has been shown that this circumstance tends to amplify macroeconomic shocks, and to exacerbate business cycles. ${ }^{6}$ These models propose a mechanism linking endogenous changes in financial agency costs and the tightening of credit markets, to the business cycle. For instance, Kiyotaki and Moore (1997) construct a model of a dynamic economy in which credit constraints arise because lenders cannot force borrowers to repay theirs debts unless the debts are secured. In such an

\footnotetext{
${ }^{3}$ The lack of theory is indeed the main problem of the sustainability approach to the current account, as observed by Milesi-Ferretti and Razin (1996).

${ }^{4}$ See Corden and Neary (1982), Van Wijnbergen, (1984), Krugman (1987) and Mansoorian (1991).

${ }^{5}$ See Gertler (1988) and Bernanke et al. (1996) for surveys on the subject. See also Bernanke et al. (1999) for some additional references and quantitative calibrations.

${ }^{6}$ See Bernanke and Gertler (1989), Greenwald and Stiglitz (1993), and Kiyotaki and Moore (1997) among others. Notwithstanding, there may be exceptions to this rule, as noted by Bacchetta and Caminal (2000).
} 
economy, durable productive assets are used by producers as collateral for loans. Hence their credit limits depend on the price fluctuations of these collateralized assets. In particular, negative shocks to the economy reduce collaterals prices, which in turn tighten credit limits and lowers down real economic activity. Thus, the functioning of credit markets works as a forceful mechanism that exacerbates the impact of shocks.

The way we introduce borrowing constraints in this paper is closely inspired by Kiyotaki and Moore's (1997) model. In our setting, the capital stock is the durable good to be used by firms as a collateral. Consequently, we assume that the credit they can obtain is proportional to the market value of their capital stock. We show that booms induced by expected productivity gains give rise to trade deficits, real exchange rate appreciations and wage increases due to the rise in the relative price of nontraded goods. These price changes relative to the domestic price of traded goods, rises costs in the traded sector and reduces the value of the stock of capital in this sector. As a consequence of the lower valuation of their collaterals, firms in the traded sector may find difficulties in financing temporary -though possibly heavy- losses. This causes an inefficiently high capacity reduction in this sector, which in turn fuels the trade deficit.

It may also be noticed that the set of technological assumptions we introduce make possible to analyze phenomena that are usually precluded in macroeconomic models. More specifically, we assume that production is subject to fixed costs, and that the capital stock in the traded sector is specific to it (i.e., it is not mobile across sectors). The common assumption of a homogenous of degree one production function usually prevents the possibility of firms suffering losses, which is a circumstance potentially very important when -as in our case- we analyze business cycle problems. And, on the other hand, taking into account that most capital goods are specialized for production in a particular sector, grants the possibility of analyzing the problems resulting form changes in the relative profitability between the traded and the nontraded sectors due to changes in the real exchange rate. On the other side, the need to make this technological framework manageable will constraint us to highly simplifying assumptions in other aspects of the technology, as well as on the path assumed for anticipated productivity shocks.

In sum, the contributions of the paper can grouped around three issues. First, the analysis of the dynamics induced by an anticipated positive productivity shock in a two-sector open economy. As already mentioned, our technological 
assumptions make possible to obtain a characterization that is richer in two principal ways than the one in previous models: ${ }^{7}$ trade deficit persistence after exchange rate depreciation, and the possibility of the boom causing a traded sector deterioration. These implications match relevant elements of some of the actual boom experiences outlined above. Second, we show that credit market imperfections exacerbate trade deficits and external debt, and cause higher (inefficient) capacity reduction in the traded sector. And third, we study the consequences on welfare and the trade deficit of some stabilization policies.

The paper is organized as follows. In the next section we set out the model. In Section 3, we characterize the efficient equilibrium. In Section 4, credit constraints are introduced, and the deviations of some key variables (the capital stock in the traded sector, the trade deficit and the real exchange rate) from their efficient equilibrium paths are analyzed. In Section 5, the consequences of fiscal stabilization policies are explored. In the last section we conclude. Most mathematical details are collected in the final Appendix.

\section{A Two-Sector Small Open Economy Model}

We consider a small open economy with exogenous interest rate, $r$, and three types of goods: capital goods, nontraded consumption goods, and traded consumption goods. Capital goods production uses only labor. Nontraded good production uses only labor, as well. Production of traded good uses capital and labor. Yet, for the shake of simplicity, we assume that labor is only needed to perform some overhead maintenance services of the capital goods. In particular, every unit of capital needs $A_{T} / \mu$ units of labor per period to be maintained; otherwise, that unit of capital is completely spoiled. ${ }^{8}$ This technology seems to be the simplest allowing for losses in one sector while the other is breaking even. The following equations set out the production technology and the dynamics of the stock of capital:

$$
\begin{gathered}
Q_{N}(t)=A_{N}(t) L_{N}(t) \\
Q_{T}(t) \leq K(t)
\end{gathered}
$$

\footnotetext{
${ }^{7}$ Murphy (1986), which assumes perfect capital stock mobility across sectors in a two-period model, is the basic reference. Obstfeld and Rogoff (1996) contains a general account of the literature on the subject.

${ }^{8}$ Since the nontraded good is made out of labor, it would be very simple to consider that nontraded goods are used as well as an input in the production of traded goods.
} 


$$
\begin{gathered}
K(t)=\frac{A_{T}(t) L_{M}(t)}{\mu} \text { if } A_{T}(t) L_{M}(t) \leq \mu K\left(t^{-}\right) ; \\
\dot{K}(t) \equiv I(t)=A_{T}(t) L_{I}(t) \\
I \geq 0 .
\end{gathered}
$$

where $Q_{N}$ is production of nontraded goods, $A_{N}$ is labor productivity in the nontraded sector, $A_{T}$ is labor productivity in those sectors related to the traded good (namely, capital maintenance services and the production of capital goods), $Q_{T}$ is the production of traded goods, $K$ is the stock of capital, $I$ is investment (i.e., the production of capital goods), $K\left(t^{-}\right)$is the left hand side limit of $K(t)$, and $L_{N}, L_{M}$ and $L_{I}$ are, respectively, the labor used in the production of nontraded goods, in maintenance services of capital goods and in the production of capital goods. Profit maximization implies that (2) is always satisfied with equality. Equation (3) implies that the capital path is lower semicontinuous. Labor is inelastically supplied and equal to one. Hence equilibrium in the labor market implies

$$
L_{N}+L_{M}+L_{I}=1
$$

Firms' maximizing behavior and arbitrage imply:

$$
\begin{gathered}
I(t)\left[w(t)-A_{T}(t) p_{K}(t)\right]=0 ; \\
w(t)=p_{N}(t) A_{N}(t) ; \\
r p_{K}(t)=1-\mu \frac{w(t)}{A_{T}(t)}+\dot{p}_{K}(t) ;
\end{gathered}
$$

where the traded good price is taken as the numeraire, $w$ is wage, $p_{N}$ is the nontraded good price, and $p_{K}$ is the price of a unit of capital.

Consumers solve the following program:

$$
\operatorname{Max}_{C_{N}(t), C_{T}(t)} \int_{0}^{\infty} e^{-\rho t} \log \left[C_{N}(t)^{\gamma} C_{T}(t)^{1-\gamma}\right] d t ;
$$

subject to

$$
\begin{gathered}
\dot{W}(t)=r W(t)+w(t)-\left[p_{N}(t) C_{N}(t)+C_{T}(t)\right] ; \\
\lim _{t \rightarrow \infty} e^{-r t}=0 ; \\
W(0)=W_{0} .
\end{gathered}
$$


where $C_{N}$ and $C_{T}$ are each good consumption, and $W(t)$ is domestic wealth; i.e. $W(t)=p_{K}(t) \cdot K(t)-D(t), D(t)$ being foreign debt. We assume $r=\rho$. Hence denoting by $E$ consumption expenditure, the first order conditions of (8) imply:

$$
\begin{gathered}
\gamma C_{T}(t)=(1-\gamma) C_{N}(t) p_{N}(t) \\
E=p_{N}(t) C_{N}(t)+C_{T}(t)=r\left[W(0)+\int_{0}^{\infty} e^{-r t} w(t) d t\right] .
\end{gathered}
$$

Therefore $E$ is independent of $t$. The following equations correspond to equilibria in the good markets and to the dynamics of the balance of payments:

$$
\begin{gathered}
Q_{N}(t)=C_{N}(t) ; \\
T D(t)=C_{T}(t)-Q_{T}(t) ; \\
\dot{D}(t)=T D(t)+r D(t)=C A D(t) ;
\end{gathered}
$$

where $T D(t)$ is the trade deficit, and $C A D(t)$ is the current account deficit. Given the initial conditions $K_{0}$ and $D_{0}$, together with $A_{N}(t)$ and $A_{T}(t)$, the above equations determine the dynamic equilibrium of the model.

\section{Positive Productivity Shocks: The Efficient Path}

We now study the dynamics induced by an anticipated positive labor productivity shock in the traded sector, which may or may not be matched by a similar shock in the nontraded sector. At time zero the following productivity path is realized: $A_{N}(t)=A_{T}(t)=1$ for $t \in[0, \tau)$; and $A_{T}(t)=\lambda, A_{N}(t)=\delta \cdot \lambda, \lambda>1, \lambda \cdot \delta \geq 1$, for $t \geq \tau .^{9}$

Our analysis will focus on the dynamics up to $\tau$. The reason is that losses, binding borrowing constraints and capacity reduction in the traded sector, if any, would occur only before at $\tau$ the productivity gains are obtained. An anticipated productivity shock raises permanent income, and therefore it implies an immediate increase in demand in both sectors (because of consumption smoothing). By

\footnotetext{
${ }^{9}$ All propositions are true and all proofs are done for the more general case of $\lambda>1$, and $\delta>0$. Nonetheless, since we are only interested in positive productivity shocks, we prefer to set the additional restriction in the text to be consistent with our verbal arguments. Besides, notice that the Balassa-Samuelson hypothesis of higher productivity gains in the traded sector implies $\delta<1$.
} 
contrast, production in any sector can only be raised in the short run (i.e., up to $t=\tau$ ) by reducing it in the other sector. This can be done through a reallocation of labor. In the traded sector, the demand increase may be matched by an increase in imports. On the other side, in the nontraded sector, the demand increase has to be matched by a combination of price and output increases. The price increase implies higher wages (see equation (6)). Wage and nontraded price increases imply in turn a real exchange rate appreciation, and a rise in the costs of production in the traded sector. As a result, firms in the traded sector may suffer losses.

From $\tau$ on, the equilibrium path of the model is rather conventional. Nonetheless, for the shake of completeness, in the next subsection we briefly give a formal characterization of the that path from $\tau$ onwards, starting from any given $K(\tau)$ and $D(\tau), K(\tau)<K^{S}\left(A_{T}=\lambda, A_{N}=\delta \cdot \lambda\right)$, where the superscript $S$ indicates steady state values.

\subsection{Transitional Dynamics with Constant Technology}

From $\tau$ on, productivity gains will offset losses in the traded sector, and will prompt investment. Both the productivity and the capital stock increases will give rise to a monotone expansion in traded output, high enough to eventually satisfy domestic demand and interest payments of the accumulated external debt.

Since initial capacity $K(\tau)$, is assumed to be below steady state values, a monotone convergent path to the steady state $(I(t)>0)$ and equation (5) imply $p_{K}(t)=\delta \cdot p_{N}(t)$, for $t \geq \tau$. From this and (7) we get a differential equation whose unique stable solution is $p_{K}(t)=p_{K}^{S}, t \geq \tau$, where

$$
p_{K}^{S}=\frac{1}{\mu+r} .
$$

Therefore we also have $p_{N}(t)=p_{K}^{S} / \delta \equiv p_{N}^{S}$. This implies the usual result that the higher the bias of productivity gains in favor of traded goods (i.e., the lower $\delta$ ), the higher will be the increase in nontraded goods price and in the real exchange rate.

The same constant nontraded good price will clear the nontraded market at any point of time since nontraded output is constant, and demand is given by a constant consumption expenditure. On the other side, the demand for maintenance services will be increasing, as a result of an increasing stock of capital. This implies that $L_{I}$-and therefore investment- will be decreasing in 
order to satisfy the labor market equilibrium condition. From (4)-(12) and (14), and taking into account that $Q_{T}(t)=K(t)$, we obtain:

$$
\begin{gathered}
\dot{K}(t)=(1-\gamma) \lambda-\gamma r K(\tau)-\mu K(t)+\gamma(\mu+r) r D(\tau) ; \\
T D(t)=\left[K^{S}-K(\tau)\right]\left[e^{-r(t-\tau)}-r p_{K}^{S}\right]-r D(\tau) \\
K^{S}=\frac{1}{\mu}[(1-\gamma) \lambda-\gamma r K(\tau)+\gamma(\mu+r) r D(\tau)]
\end{gathered}
$$

From (16) the other balance of payments variables' paths can be obtained. Notice that as long as $D(\tau) \geq 0$ and $K(\tau)<K^{S}$, there will be initial trade deficits. In the long run, capacity in the traded sector will have to be high enough to satisfy the domestic consumption of traded goods, and to pay -with exports- for interests on the external debt. Once this condition is satisfied, the current account is balanced and capital and external debt have reached their stationary level. Note that the steady state equilibrium depends on the initial amounts of capital and external debts. $K^{S}$ is higher, the higher is $D(\tau)$ since this will imply higher stationary debt, and therefore larger stationary exports to pay for interests. Furthermore, $K^{S}$ is lower the higher is $K(\tau)$ since this allows for lower debt accumulation during the transition path; and therefore it implies lower interest payments in the steady state. Figure 2 depicts the balance of payments variables' paths for the whole period $t \in[0, \infty)$.

\subsection{Anticipated Shocks}

We now analyze the dynamics in period $[0, t)$. For simplicity, we will assume that at time zero, when the productivity shock is announced, $D_{0}=0$ and that the capital stock is in its previous steady state (which had been approached from below $)$; i.e., $K_{0}=K^{S}\left(A_{N}=A_{T}=1\right) \equiv(1-\gamma) /(\mu+\gamma r)$. As already observed, an anticipated productivity shock raises consumption expenditure to a new constant level, as soon as the new productivity path is realized. The expenditure increase in the nontraded sector is initially matched by a rise in its relative price. This raises wages, and therefore increases (maintenance) costs in the traded sector. Eventually, if the cost rise is high enough, expected losses in the traded sector would bring $p_{K}$ to non-positive values; hence making it optimal to dump all or part of this sector capital stock. We will refer to this as a capacity reduction. Capacity reduction would imply a transfer of labor from the traded sector to the nontraded one. This provides the second mechanism for re-equilibrating the 
nontraded market. Hence the first adjusting mechanism in the nontraded sector is the increase in its relative price; and, as long as this increase is high enough to bring $p_{K}$ to zero, a quantity adjustment would take place as well.

Since $p_{K}(t)=p_{K}^{S}$ for $t \geq \tau$, the price of a capital unit for $t \in[0, \tau)$ is given by:

$$
p_{K}(t)=\int_{t}^{\tau}\left[1-\mu p_{N}(q)\right] e^{-r(q-t)} d q+\frac{e^{-r(\tau-t)}}{\mu+r} .
$$

As soon as -at time zero- the new productivity path is known, the fall in $p_{K}$ and the capacity reduction in the traded sector -if any- will take place instantaneously. Let us denote by $p_{K}\left(0^{-}\right)$and $p_{K}(0)$ the price of capital at time zero, before any adjustment of its stock has taken place, and just after it has taken place, respectively. And let us denote by $K(0), K(0) \leq K_{0}$ the amount of capital that is left at the beginning of the new equilibrium path. Clearly, if $p_{K}\left(0^{-}\right)>0$, no reduction of capacity would take place. On the other hand, a partial reduction of the traded capacity is compatible only with $p_{K}(0)=0$. Finally, $p_{K}(0)<0$ implies $K(0)=0$. Relationships between the price of capital and the capacity that remains at time zero once the new productivity path is known, are synthesized by:

$$
p_{K}(0) \cdot\left[K(0)-K_{0}\right] \cdot K(0)=0 .
$$

Once adjustments at time zero have taken place, most variables including $p_{N}$ and $K$ remain constant until $\tau$ (see Lemma 8 in the Appendix.). We will denote by $p_{N}$ the constant price of the nontraded good over $[0, \tau)$, and by $K(0)$ the constant stock of capital over that same interval $[0, \tau)$. The following system of equations -which is obtained from (4), (6), (9), (10) and (18)- and (19) allow us to solve for $p_{N}, p_{K}, K(0)$ and $E$ :

$$
\begin{aligned}
E & =r p_{K}(0) K(0)+p_{N}\left(1-e^{-r \tau}\right)+\frac{\lambda}{\mu+r} e^{-r \tau} ; \\
1 & =\mu K(0)+\frac{\gamma E}{p_{N}} ; \\
p_{K}(0) & =\left[\frac{1-\mu p_{N}}{r}\right]\left(1-e^{-r \tau}\right)+\frac{e^{-r \tau}}{\mu+r} .
\end{aligned}
$$

Taking into account the solutions to this system, the positive relationship between the real exchange rate and $p_{N}$, and the following equation (12') -which is obtained from (2), (9), (10) and (12)-, we will be able to formulate the main 
implications of the model.

$$
T D=(1-\gamma) E-K(0)
$$

We will distinguish three sets of anticipated productivity shocks depending on their effects on this initial stock of capital. These sets correspond to the three possible ways to fulfill (20). We call Region I to the set of pairs $(t, \lambda)$ such that in the new equilibrium path we have $K(0)=K_{0}$. Hence for this region's shocks, the rise in $p_{N}$ needed to clear the nontraded market does not reach the point where capacity reduction in the traded sector occurs. Region II is the set of pairs $(t, \lambda)$ giving rise to a new path where $0<K(0)<K_{0}$; hence the rise in $p_{N}$ needed to clear the nontraded market implies $p_{K}=0$. And we call Region III to the set of pairs $(t, \lambda)$ implying $K(0)=0$ in the new path; i.e., the nontraded market equilibrium requires an increase in $p_{N}$ high enough to cause $p_{K}<0$.

Proposition 1 If anticipated positive productivity shocks are strong enough, capacity in the traded good sector will be reduced, and could even be carried out to zero. Formally, there exists $\lambda^{P}(\tau)>0$ such that, for any $\tau>0$, if $\lambda>\lambda^{P}(\tau)$ then the shock $(\tau, \lambda)$ implies $K(0)<K_{0}$; and there exists $\lambda^{F}(\tau), \lambda^{F}(\tau)>\lambda^{P}(\tau)$, such that if $\lambda>\lambda^{F}(\tau)$ then $K(0)=0$.

Proof: See Appendix.

Clearly, $\lambda^{P}(\tau)$ and $\lambda^{F}(\tau)$ are, respectively, the frontiers between regions I and II, and between regions II and III; i.e., Region $\mathrm{I}=\left\{(\tau, \lambda) \in \Re_{+}^{2}: \lambda \leq \lambda^{P}(\tau)\right\}$; Region II $=\left\{(\tau, \lambda) \in \Re_{+}^{2}: \lambda>\lambda^{P}(\tau)\right.$ and $\left.\lambda<\lambda^{F}(\tau)\right\}$; Region III $=\{(\tau, \lambda) \in$ $\left.\Re_{+}^{2}: \lambda \geq \lambda^{F}(\tau)\right\}$. They are depicted in Figure 1. It is easy to check formally that -as it is shown in this figure- strong positive and medium run anticipated productivity shocks are those more likely to force a capacity reduction in the traded sector. Positive productivity shocks anticipated for the very short run do not give the time to accumulate enough losses in the traded sector. On the other hand, very far foresighted shocks raise expenditure very moderately, and are therefore easily accommodated by low $p_{N}$ increases. Now, assuming constant relative prices abroad, the real exchange rate directly depends on $p_{N}$. The next proposition characterizes the real exchange rate and the balance of payments' paths for $t \in[0, \tau)$. These paths are depicted in Figure 2 .

Proposition 2 Independently of their sectorial structure -which is given by $\delta$ anticipated positive productivity shocks always give rise to real exchange rate appreciation, at least up to $\tau$, and to trade and current account deficits. These 
deficits are monotonically increasing with respect to the magnitude $\lambda$ of the productivity shock, and decreasing with respect to the horizon $\tau$. Furthermore, they persist after productivity gains -and possible depreciations-in $\tau$, and depict a continuous path at this point. On the other hand, external debt at time $\tau$ is monotonically increasing in both $\lambda$ and $\tau$.

Proof: See Appendix.

Exchange rate dynamics result from the overlapping of a short run and a long run effect. In the short run, the demand jump confronts a constant production capacity, and raises the nontraded good price and therefore the real exchange rate. In the long run, it is the relative productivity gains $\delta$ that determine the real exchange rate. If future productivity gains affect in a similar way both sectors -i.e., if $\delta$ is close to one- the real exchange rate appreciation will be only transitory $(\delta=1$ implies no real exchange rate appreciation at all in the long run). By contrast, productivity gains affecting almost only the traded sector -i.e., $\delta$ close to $1 / \lambda$ - give rise to long run real exchange rate appreciations which could surpass the short run appreciation.

Trade deficits are higher the higher is $\lambda$ because expected productivity growth raises expenditure, and because -in regions II and III- it reduces traded capacity (and, therefore, traded production). Appreciation of the real exchange rate is clearly the consequence of the nontraded relative price increase, assuming foreign prices to be constant. Obviously, both real exchange rate and trade balance are endogenous in this model, and therefore arguing any causality from the first to the second would be spurious. Current account deficit will be growing as a result of increasing interest payments.

The persistence of trade deficits after the dollar depreciation in the second half of the mid-eighties was a puzzling phenomenon that attracted very much attention (see Krugman and Baldwin, 1987). Our model points to the specialization of each capital stock for production in the sector for which it was built, and to the domestic traded sector capacity stagnation -or even reduction- during the booming period of exchange rate appreciation, as the reasons for the slow recovery of the trade balance after the turning point $\tau$.

\section{Equilibrium with Borrowing Constraints}

Borrowing constraints are pervasive phenomenon in actual economies which tends to be the consequence of agency problems. According to the discussion and the 
literature quoted in the Introduction on the use by firms of their productive assets as collateral, we assume that, at any point of time, firms cannot borrow more than a portion $c(0<c<1)$ of their capital stock value. In our model, the need for borrowing after the anticipated productivity shock has been realized, arises only in the traded sector as a result of the necessity to finance the possible losses caused up to $\tau$ by the real exchange rate appreciation and the cost increase. Hence the most useful way to set out the borrowing constraint is establishing that accumulated losses -per unit of capital- cannot exceed at any point of time a proportion $c$ of the value of a capital unit:

$$
\int_{0}^{t}\left[\mu p_{N}(q)-1\right] e^{r(t-q)} d q \leq c p_{K}(t) ; t \in(0, \tau) .
$$

Should the constraint be binding, firms will be unable to finance all their losses (caused by overhead costs), and capacity in the traded sector will have to be reduced. Notice that $c=1$ would imply that there are no borrowing constraints. ${ }^{10}$ It can be shown (see Lemmas 9, 10 and 11, respectively, in the Appendix) that: a) if this constraint is expected to be binding for some $t$, capacity will be reduced below $K_{0}$ from the very beginning of the new path; b) after capital adjustment at time zero, $K(t)$ and $p_{N}(t)$ remain constant up to $\tau$; and c) if constraint (21) is binding for some $t$, it would be binding for $t=\tau$. This implies that we only need to take the constraint into account at $\tau$. Hence (21) can be simplified to:

$$
\left[\mu p_{N}-1\right]\left[\frac{e^{r \tau}-1}{r}\right] \leq c p_{K}^{S}
$$

Now, with credit market imperfections, the following equation substitutes (19):

$$
\left[c p_{K}^{S}-\left[\mu p_{N}-1\right]\left[\frac{e^{r \tau}-1}{r}\right]\right] \cdot\left[K(0)-K_{0}\right] \cdot K(0)=0 .
$$

The partition on the set of possible shocks into three regions, depends now on the value of $c$. Again, for a given $c$, we call Region I' the set of pairs $(\tau, \lambda)$ such that in the new equilibrium path $K(0)=K_{0}$. Region II' is the set of pairs $(\tau, \lambda)$ such that in the new equilibrium $0<K(0)<K_{0}$ (notice that now, points in this Region II' does not necessarily imply $p_{K}=0$; in fact, $p_{K}>0$ will be the case). And Region III' is the set of pairs $(\tau, \lambda)$ that brings about $K(0)=0$

\footnotetext{
${ }^{10}$ Hitting the constraint with $c=1$ would imply a negative value of capital at time zero. Therefore, the very optimal equilibrium would imply that some capacity should be disposed of, up to the point to satisfy the constraint with equality.
} 
in the new equilibrium (again, now this does not require $p_{K} \leq 0$ ). We will denote by $\lambda^{P}\left(c, \tau^{\prime}\right)$ the frontier of shocks giving rise to capacity reduction; i.e., if $\lambda^{\prime}>\lambda^{P}\left(c, \tau^{\prime}\right)$ then $\left(\tau^{\prime}, \lambda^{\prime}\right)$ imply $K(0)<K_{0}$. And by $\lambda^{F}(c, \tau), \lambda^{F}(c, \tau)<\lambda^{F}(\tau)$, the frontier of shocks giving rise to zero capacity; i.e., if $\lambda^{\prime} \geq \lambda^{F}\left(c, \tau^{\prime}\right)$ then $\left(\tau^{\prime}, \lambda^{\prime}\right)$ imply $K(0)=0$. We say that firms have limited access to the financial market whenever $0<c<1$. Whenever limited access to the financial market forces traded firms to dispose of some capital without $p_{K}$ being zero, we will have an inefficient equilibrium.

Proposition 3 If firms have limited access to credit markets, there is a nonempty set of shocks $\Omega(c)=\left\{(\tau, \lambda) \in \Re_{+}^{2}: \lambda>\lambda^{P}(c, \tau)\right.$ and $\left.\lambda<\lambda^{F}(\tau)\right\}$ that would drive the economy into inefficient equilibria. In all these equilibria, capacity reduction in the traded sector is higher than in the efficient equilibrium.

Proof: See Appendix.

In a similar way as in Section $3, \lambda^{P}(c, \tau)$ and $\lambda^{F}(c, \tau)$ are the frontiers between regions I' and II'; and regions II' and III', respectively; i.e., Region I' $=\{(\tau, \lambda) \in$ $\left.\Re_{+}^{2}: \lambda \leq \lambda^{P}(c, \tau)\right\}$, Region $\mathrm{II}^{\prime}=\left\{(\tau, \lambda) \in \Re_{+}^{2}: \lambda>\lambda^{P}(c, \tau)\right.$ and $\left.\lambda<\lambda^{F}(c, \tau)\right\}$, and Region III' $=\left\{(\tau, \lambda) \in \Re_{+}^{2}: \lambda \geq \lambda^{F}(c, \tau)\right\}$. These regions are depicted in Figure 3. Moreover, $\lambda^{P}(\tau)=\lambda^{P}(1, \tau)$, and $\lambda^{F}(\tau)=\lambda^{F}(1, \tau)$. Notice that $\Omega$ is a set of intermediate shocks, both in their strength and in the anticipation with which they are foreseen; i.e., for every $t$, the interval $\left[\lambda^{P}(c, \tau), \lambda^{F}(\tau)\right]$ is bounded away from zero and infinity; and for any $\lambda^{\prime}$ in the domain of $\lambda^{P}(c, \tau)$, there exists $\tau\left(\lambda^{\prime}\right)$ and $\tau^{\prime}\left(\lambda^{\prime}\right)$ such that if $\tau<\tau^{Z}\left(\lambda^{\prime}\right)$ or $\tau>\tau^{Z \prime}\left(\lambda^{\prime}\right)$ then there is no inefficiency (since region I' completely surrounds from below the set $\Omega$ ). Hence low intensity shocks do not give rise to losses in the traded sector, while very strong shocks would completely wipe out firms in this sector even in the efficient equilibrium. On the other hand, shocks foreseen for the very near future do not give the time to accumulate enough losses to hit the borrowing constraint; and very far foresighted shocks have a very limited effect on current demand, and therefore on relative prices.

Now we turn to the consequences of this market failure on the balance of payments. The question is whether in the inefficient path, deficits, external debt and real exchange rate appreciation tend to be higher or lower than in the efficient path.

Proposition 4 Shocks driving the economy to equilibria with borrowing constrained firms -i.e., shocks in $\Omega$ - give rise to higher trade deficits, higher debt, 
and lower exchange rate appreciation than in the efficient path, at least up to $\tau$.

Proof: See Appendix.

Higher capacity reduction in the traded sector implies more imports (although permanent income, and therefore expenditure, is lower in the inefficient equilibrium). On the other hand, less capacity implies less maintenance services, which reduces demand pressures in the nontraded good market. Hence adjustment of the nontraded good market requires a lower increase in its relative price, thereby giving rise to a lower real exchange rate appreciation. As in the efficient equilibrium, the deficit is constant for the whole interval $0 \leq t \leq \tau$. In Figure 4 we compare the trade deficit in the efficient path with that in the borrowing constrained path, as a function of $\lambda$ and for some given $\tau^{\prime}$. Of course, this deficit can only differ for shocks in $\Omega$ (i.e., for $\lambda$ between $\lambda^{P}\left(c, \tau^{\prime}\right)$ and $\lambda^{F}\left(1, \tau^{\prime}\right)$ ); and, according to the proposition, the upper line is the one showing the trade deficit for equilibria with binding borrowing constraints.

Note that this market failure does not associate an excessive current account deficit to an excessively appreciated currency. Real exchange rate appreciation is not caused by the inefficient working of the market; in fact this appreciation is part of the correct functioning of the market mechanisms, and is higher in the efficient equilibrium. On the other hand, the fact that in our model inefficiency causes larger trade deficits, raises the question of whether a large deficit could be used as a partial signal of being in an inefficient path. Unfortunately, the informational content of that signal alone seems to be very low. For instance, deficits can be as large as we may think of with no inefficiency at all, as implied by Proposition 3 (take a very large $\lambda$ with a very short $\tau$ ). Moreover if external deficits are measured by the increase in external debt (to take account of the temporal dimension of the problem), we obtain that debt measured at $\tau$ is always increasing in $\tau$ (as implied by Propositions 2 and 4); but, on the other hand, for any $\lambda$, if $\tau$ is high enough there is no inefficiency at all (as noticed after Proposition 3). Hence, although external debt grows with inefficiency in our model, it does not seem to be a good signal of inefficiency either. And finally, the stated implications of inefficiency over the balance of payments' path are specific to the particular market failure we assume. Since other market failures could have opposite implications, the observation of any level of current account deficit and external debt can hardly provide by itself the grounds for government intervention, without exploring the main market failures that could be affecting the equilibrium path. 


\section{Economic Policy}

Clearly, policies that directly compensate for the market failure, like government lending to firms in the traded sector or subsidies that have to be refunded once firms start to have profits, would eliminate the inefficiency. Nevertheless, it is likely that the same informational problems that prevent firms from privately getting all the funds they need would preclude an easy implementation of those policies. In this section we study the effects on welfare and the current account of two types of (distortionnary) fiscal policies; namely, tax shifts that distort intertemporal prices (by raising a consumption tax on both goods up to $\tau$ ), and tax shifts that additionally distort the intratemporal relative price (by raising a consumption tax only upon one of the goods).

In the following, several points have to be beard in mind. First, we restrict the analysis to paths arising from shocks in $\Omega$ for reasons that are self-evident. Second, any policy is assumed to be applied only up to $\tau$ since thereafter the equilibrium path is efficient for any pair of state variables $[K(t), D(t)]$. And third, it is assumed that yields obtained (or costs incurred) by the government as a result of these policies, are refunded (or financed, respectively) in a lump sum way to (from, respectively) domestic residents.

A Consumption Tax on Both Goods

Let us denote by $\theta$ a consumption tax. Hence after-tax domestic prices are:

$$
\begin{aligned}
& p_{T}^{\prime}=1+\theta \\
& p_{N}^{\prime}=p_{N}(1+\theta) .
\end{aligned}
$$

Proposition 5 For shocks in Region II', a consumption tax would increase welfare and would reduce the trade deficit. ${ }^{11}$

Proof: See Appendix.

Raising a consumption tax up to $\tau$ makes current consumption more expensive with respect to future consumption, which reduces it in physical terms. Hence this

${ }^{11}$ It can be shown that if

$$
e^{-r \tau} \gamma r(1-c)>\left(e^{r \tau}-1\right)(\mu+r)+r c
$$

a positive tax would be welfare improving, even if their yields were not refunded back to residents but wasted or given to non-residents! 
policy acts as a stabilization policy, shifting aggregate demand from the current period to the future. This lowers the trade deficit and moderates the increase in the nontraded good price (when used by firms as an input); which in turn reduces losses in the traded sector, and helps saving some capital from disposal. The value of the capital that is saved is higher than the cost of distorting the intertemporal choice of consumption (for $\theta$ small, the distortion on consumption has a second order effect on welfare, but there is a first order effect on saving capital which has an strictly positive price). Finally, the reason for this policy to be ineffective for some extreme shocks in $\Omega$ belonging to Region III' is because for shocks close enough to Region III, the small amount of capital that could be saved with a the tax is worth less than the welfare loss caused by the distortion in consumption. ${ }^{12}$

\section{A Consumption Tax on the Nontraded Good}

Since the inefficiency in our model is caused by a problem specific to one sector, it is likely that policies more sector specialized could be more effective. As we will see, this is the case with taxes. Assume now that only nontraded goods are taxed with a consumption tax that we denote by $\theta_{N}$. Hence the after-tax price of the nontraded good when used for consumption, $p_{N}^{\prime}$, is:

$$
p_{N}^{\prime}=p_{N}\left(1+\theta_{N}\right) .
$$

Proposition 6 For any shock in $\Omega$ there is a positive consumption tax on the nontraded good that would bring the economy back to the efficient equilibrium.

Proof: See Appendix.

It may be somewhat surprising that in an economic boom, when the rise of the nontraded good price is a source of problems, an optimal policy implies feeding this increase with a specific consumption tax on these goods. But recall that the nontraded price increase is part of the efficient adjustment mechanism that is partially substituted in the inefficient path by an excessive disposal of capital in the traded sector. The rise in the nontraded consumption tax has the virtue to encompass a discriminatory price increase that lowers nontraded consumption down to the efficient path level, without rising costs in the traded sector. Although it is clear that reaching the very first best with this policy

\footnotetext{
${ }^{12}$ As we approach Region III, the value of a unit of capital tends to zero but the tax needed to save any positive amount of capital is bounded away from zero.
} 
is a result that would not carry on to more general models, the reason why it is specially effective seems quite general. On the other hand, it may be noted that return to the efficient equilibrium implies that this tax policy simultaneously reduces the trade deficit and increases the real exchange rate.

The compensatory lump sum tax refunds that would be necessary in order to satisfy the public budget constraint, may be difficult to implement. A possible alternative would be to choose opposite sign shifts in a consumption tax on the traded good, $\theta_{T}$, and the nontraded good $\theta_{N}$, so that the total tax yields remain constant. It can be proved that an optimal choice of these instruments implies to raise $\theta_{N}$ and to lower $\theta_{T}$, and that this would improve welfare for at least shocks in Region II'; although first best would not be attained anymore. Moreover, it can also be proved that a positive tariff could also be welfare improving, and that it would raise the real exchange rate and reduce the trade deficit.

\section{Concluding Comments}

In this paper we have investigated the consequences of anticipated productivity shocks. We have gone further from the usual technological assumptions to incorporate the possibility of firms having losses, and of being unable to freely transfer their capital stock from one sector to the other. In this setting we have shown how economic booms may be responsible for the partial destruction of a country's exporting sector, and why trade deficits will tend to persist after attaining expected productivity gains in the traded sector and after the domestic currency has depreciated. Furthermore, we have established that agency problems in the credit markets exacerbate trade deficits, and bring about a still higher capacity reduction in the traded sector.

In these circumstances, some conventional stabilization policies, may be welfare improving, though some new alternatives may be more effective. For instance, taxing nontraded goods may be a powerful tool since the source of the problem in an economic boom is neither the trade deficit nor the real exchange rate appreciation, but that the rise in the nontraded good price and wages is unbearable for the traded sector. Hence helping to clear the nontraded market without increasing traded sector's costs, as with a specific consumption tax, may be a very effective policy. Still, aggregate stabilization policies may be useful if sector discriminating policies are not possible. On the other hand, it should be noted that the fiscal policies we have analyzed are still available in trade and 
monetary unions like the European one, and that they could compensate for the suppression of trade and exchange rate policies.

With respect to the exchange rate dynamics the model predicts an appreciation in the short run, as a result of the anticipated productivity shock. But this short run behavior may be followed in the long run by a depreciation, or to the contrary, by further appreciations. The reason is that the exchange rate dynamics in this setting is the result of two overlapping effects: one arising from the immediate aggregate demand rise, and another arising from the longer run productivity gains. Depending on whether the productivity gains are strongly biased towards the traded sector or not, the real exchange rate appreciation will be permanent, or either, only transitory.

Although our model is a real one, there is an important remark to be made on implications for monetary economies. Assuming the price of the traded goods to be constant, the rise in the relative price of the nontraded goods implies higher inflation. This is a common problem in actual monetary economies during booms that governments may likely try to control with a contractionnary monetary policy. Since the traded sector may be undergoing credit constraints, this contractionnary monetary policy would probably be specially damaging for this sector and can hardly be a good policy. By contrast, as we have shown, a contractionnary fiscal policy would help.

Finally, there is a general consideration to be made. Traditionally, policies intended to maintain "external balance" have been an important part of macroeconomics. In fact, external balance is still sometimes mentioned as a possible objective for monetary policymakers (see, for instance, Blinder,1998, p.3). From a modern perspective, market failures may justify government intervention, but it is unclear why we should care about external deficits. Yet, traditional macroeconomics' concern about the current account could be rationalized if large and persistent deficits were frequently associated with market failures. In this respect, this paper gives a most positive answer to the questions of whether the assumed market failure increases the current account deficit, and whether policies that reduce this deficit increase welfare (so they can be used, at least, as second best policies). However, more work will have to be done before we can give a detailed answer to the question of whether large and persistent trade deficits should still be taken as a general signal of deeper underlying problems. 


\section{References}

[1] Bacchetta, P. and R. Caminal (2000): "Do Market Imperfections Exacerbate Output Fluctuations?", European Economic Review, 44, 449-468.

[2] Blinder, A.S. (1998): Central banking in theory and practice, MIT Press.

[3] Bernanke, B. S. and M. Gertler (1989): "Agency Costs, Net Worth, and Business Fluctuations", American Economic Review, 79, 14-31.

[4] Bernanke, B. S., M. Gertler and S. Gilchrist (1996): "The Financial Accelerator and the Flight to Quality", The Review of Economics and Statistics, LXXVIII, 1-15.

[5] Bernanke, B. S., M. Gertler and S. Gilchrist (1999): "The Financial Acceletator in a Quantitative Business Cycle Framework", in J.B. Taylor and M. Woodford (Eds.), Handbook of Macroeconomics, Volume 1, chapter 21, Elsevier Science B.V.

[6] Corden, W.M. and Neary, J.P. (1982): "Booming sector and deindustrialization in a small open economy", Economic Journal, 92, 825-848.

[7] Fernández de Córdoba, G. and T. Kehoe (2000): "Capital Flows and Real Exchange Rate Fluctuations Following Spain's Entry into the European Community", Journal of International Economics, 51, 49-78.

[8] Gertler, M. (1988): "Financial Structure and Aggregate Economic Activity: An Overview", Journal of Money, Credit and Banking, 20, 559-588.

[9] Greenwald, B. and J. Stiglitz (1993): "Financial Market Imperfections and Business Cycles", Quarterly Journal of Economics, 108, 77-104.

[10] Kiyotaki, N. and Moore, J. (1997): "Credit Cycles", Journal of Political Economy, 105, 211-248.

[11] Krugman, P. (1987): "The narrow moving band, the dutch disease, and the competitive consequences of Mrs. Thatcher", Journal of Development Economics, 27, 41-55.

[12] Krugman, P. and R.E. Baldwin (1987): "The Persistence of the U.S. Trade Deficit", Brookings Papers on Economic Activity, 1, 1-43. 
[13] Mansoorian, A. (1991): "Resource discoveries and 'excessive' external borrowing", Economic Journal, 101, 1497-1509.

[14] Milesi-Ferretti, G.M. and Razin, A. (1996), "Current account sustainability: selected East Asian and Latin American experiences", NBER Working Paper no 5791.

[15] Murphy, R.G. (1986): "Productivity shocks, nontraded goods and optimal capital accumulation", European Economic Review, 30, 1081-1095.

[16] Obstfeld, M. and Rogoff, K. (1995): "Exchange Rate Dynamics Redux", Journal of Political Economy , 103, 624-660.

[17] Obstfeld, M. and Rogoff, K. (1996): Foundations of International Macroeconomics, MIT Press.

[18] Van Wijnbergen, S. (1984): "The 'Dutch Disease': A disease after all?", Economic Journal, 94, 41-55.

\section{Appendix}

Lemma 7 Anticipated positive productivity shocks imply $K(t)$ and $p_{N}(t)$ are constant for $t \in[0, \tau)$, with $p_{N}(t)>p^{S}$ and $K(0) \leq K_{0}$.

Proof. We will proceed through three claims.

Claim 1: If an anticipated positive productivity shock gives rise to some capacity reduction at some $t^{\prime} \in[0, \tau)$, then cash flow $\left(1-p_{N}(t) \cdot \mu\right)$ cannot be positive at any point in $[0, \tau)$.

Let us assume to the contrary that there exist $t^{\prime}$ and $t^{\prime \prime} \in[0, \tau)$ such that $K\left(t^{\prime}\right)<K_{0}$ and $1-p_{N}\left(t^{\prime \prime}\right) \cdot \mu>0$. First notice that you would never dispose of capital while being in an interval with a strictly positive cash flow (it is always profitable to wait at least until the end of that interval to reduce capital), or up to the point to give rise to an interval with a strictly positive cash flow; i.e., if $1-p_{N}(t) \cdot \mu>0$ for $t \in[a, b)$, then $K(t) \geq K\left(a^{-}\right)$for $t \in[a, b)$. Now let $t_{m}$ be the first point of time at which disposal of capital brings the stock to its lowest level during period $[0, t)$; i.e., denoting by $\underline{K}=\min _{t \in[0, t)}\{K(t)\}$, we define $t_{m}=\min \{t \in[0, \tau): K(t)=\underline{K}\}$. Since at this point of time investment cannot be positive, equilibrium in the labor market implies $t_{m}=\min \{t \in[0, \tau)$ : 
$\left.p_{N}(t)=\underline{p_{N}}\right\}$, where $\underline{p_{N}}=\min _{t \in[0, t)}\left\{p_{N}(t)\right\}$. Clearly, $\underline{p_{N}} \leq p\left(t^{\prime \prime}\right)$; and therefore, $1-\underline{p_{N}} \cdot \mu>0$. Now, since capital can only be increased at a continuous path, we can take $\epsilon>0$ close enough to zero such that cash flow for $t \in\left[t_{m}, t_{m}+\epsilon\right)$ is positive. On the other hand, the definition of $K\left(t_{m}\right)$ implies capital is being reduced at $t_{m}$ (at least down to $K\left(t^{\prime}\right)$ for the first time). Hence a capital reduction to $K\left(t^{\prime}\right)$ in period $[0, \tau)$ and a positive cash flow at time $t^{\prime \prime}$ in that same interval, imply capital is being reduced at time $t_{m}$ up to the point to give rise to an interval with a strictly positive cash flow. But this is impossible, as stated above

Claim 2: Anticipated positive productivity shocks imply $p_{N}(t)>p_{N}^{S(0)}$ and $I=0$ for $t \in[0, \tau)$.

Anticipated positive shocks raise consumption expenditure to a higher constant level. Since labor productivity is constant up to $\tau$, the labor market equilibrium requires either a sustained rise of $p_{N}$ above its previous price $p_{N}^{S(0)}\left(=p_{K}^{S}\right)$ (in which case the first part of the lemma is proved), or a reduction in the stock of capital, high enough to compensate the increase in consumption expenditure with the reduction in demand for maintenance services. Let us assume that at some point of time this is possible without having $p_{N}(t)>p_{N}^{S(0)}$; i.e., let us assume there is some $t^{\prime}$ such that equilibrium is reached with $K\left(t^{\prime}\right)<K_{0}$ and $p_{N}\left(t^{\prime}\right) \leq p^{S}$. But since $p_{N}\left(t^{\prime}\right) \leq p_{N}^{S(0)}$ implies a positive cash flow at $t^{\prime}$, these assumptions contradict Claim 1 . Hence $p_{N}(t)>p_{N}^{S(0)}$ for $t \in[0, \tau)$. Now, using this fact and (16) we can write:

$$
\begin{aligned}
p_{K}(t)<\int_{t}^{\tau} & {\left[1-\mu p_{N}^{S(0)}\right] e^{-r(q-t)} d q+p_{K}^{S} e^{-r(\tau-t)} } \\
& =\left[\frac{1-\mu p_{N}^{S(0)}}{r}\right]\left(1-e^{-r(t-\tau)}\right)+p_{N}^{S(0)} e^{r(t-\tau)}=p_{N}^{S(0)}<p_{N}(t) ;
\end{aligned}
$$

for $t \in[0, \tau)$. Hence using (5) we conclude $I(t)=0$

Claim 3: Anticipated positive productivity shocks imply $K(t)$ and $p_{N}(t)$ are constant for $t \in[0, \tau)$.

By Claim 2 we know that $I(t)=0$ for that interval. This implies maintenance costs are non-increasing. Since $E$ is constant, $p_{N}$ is non-increasing as well. This together with (18) and $p_{N}(t)>p_{N}^{S(0)}$ (Claim 2) imply $p_{K}(t)$ is increasing. Therefore $p_{K}(t) \leq 0$ for some $t \in[0, \tau)$ would imply $p_{K}\left(0^{-}\right)<0$; hence all the capital stock adjustment -if any- would occur at time zero (so that $p_{K}(0) \geq 0$ ). Thus $K(t)$ is constant over $[0, \tau)$. This implies that the labor used for maintenance is also constant. Therefore, since $Q_{N}$ and $E$ are constant, $p_{N}(t)$ is constant over 
$[0, \tau)$

\section{Proof of Proposition 1}

Let us look for the set of shocks resulting in $0<K(0)<K_{0}$. This would happen only if $p_{K}(0)=0$. Plugging in this condition into the system (20) we obtain the value of $K(0)$. Substituting with it into the inequality $K(0)<(1-$ $\gamma) /(\mu+\gamma r)$, and solving for $\lambda$, we obtain:

$$
\lambda>\frac{\left[e^{r \tau}(\mu+r)-\mu\right]\left[1-\gamma+\gamma e^{-r \tau}+\left(\mu e^{-r \tau} / r\right)\right]}{\mu\left(1-e^{-r \tau}\right)(\gamma+\mu / r)} \equiv \lambda^{P}(\tau) .
$$

Hence for any given $\tau, \lambda>\lambda^{P}(\tau)$ implies $K(0)<K_{0}$. Notice that the function is positively defined for any non-negative $\tau$. Now let us look for the set of shocks resulting in $K(0)=0$. This occurs only if $p_{K}(0) \leq 0$. Solving for $p_{K}(0)$ in system (20) with $K(0)=0$, taking there $p_{K}(0) \leq 0$, and solving then for $\lambda$, we obtain:

$$
\lambda \geq \frac{\left[e^{r \tau}(\mu+r)-\mu\right]\left(1-\gamma+\gamma e^{-r \tau}\right)}{\mu\left(1-e^{-r \tau}\right) \gamma} \equiv \lambda^{F}(\tau) .
$$

Hence for any given $\tau, \lambda \geq \lambda^{F}(\tau)$ implies $K(0)=0$. It can be easily checked that $\lambda^{F}(\tau)>\lambda^{P}(\tau)$ for any non-negative $\tau$. Finally, notice in (A.2) that $\lambda^{P}(\tau)$ tends to infinity as $\tau$ tends to zero or to infinity (as depicted in Figure 1).

\section{Proof of Proposition 2}

Let us solve the system (20) for each of the three regions defined in the text.

a) Region I: $K(0)=K_{0}$. Substituting into (20) we obtain:

$$
p_{N}=\frac{(1-\gamma)(\mu+r)+e^{-r \tau}[\mu(\lambda-1+\gamma)+\gamma r \lambda]}{(\mu+r)^{2}\left(1-\gamma+\gamma e^{-r \tau}\right)} .
$$

From (20) and (12') we also obtain that the trade deficit is constant for this same interval:

$$
T D=\frac{(\lambda-1)(1-\gamma) e^{-r \tau}}{(\mu+r)\left(1-\gamma+\gamma e^{-r \tau}\right)}
$$

Moreover:

$$
D(t)=\left(\frac{e^{r t}-1}{r}\right) T D ; C A D(t)=e^{r t} T D ; 0 \leq t<\tau ;
$$

and

$$
D(\tau)=\frac{(\lambda-1)(1-\gamma)\left(1-e^{-r \tau}\right)}{r(\mu+r)\left(1-\gamma+\gamma e^{-r \tau}\right)} ; \lambda<\lambda^{P}(\tau)
$$


b) Region II: $0<K(0)<K_{0}$. Equation (19) and $0<K(0)<K_{0}$ imply $p_{K}(0)=0$. Substituting into (20) we get:

$$
p_{N}=\frac{[1+(r / \mu)] e^{r \tau}-1}{(\mu+r)\left(e^{r \tau}-1\right)} .
$$

Solving for $E$ with the same equations and substituting into (12') we obtain:

$$
T D=\frac{\left(\mu+r-\mu e^{-r \tau}\right)(\lambda \mu-\mu-\gamma r)-\gamma r \lambda \mu e^{-r \tau}}{\mu(\mu+r)\left[(\mu+r) e^{r \tau}-\mu\right]} .
$$

Equation (A.6) for debt and current account deficit applies again in this region. Furthermore,

$$
\begin{gathered}
D(\tau)=\frac{\left(1-e^{-r \tau}\right)}{\mu r(\mu+r)}(\lambda \mu-\mu-\gamma r)-\frac{\gamma \beta\left[r(1-\gamma)+(\mu+\gamma r) e^{-r \tau}\right]}{(\mu+r) \mu(\mu+\gamma r)} ; \\
\text { where } \beta=\frac{\lambda}{\lambda^{P}(\tau)}>1 .
\end{gathered}
$$

c) Region III: $K(0)=0$. Substituting into (20) we get:

$$
p_{N}=\frac{\gamma \lambda e^{-r \tau}}{(\mu+r)\left(1-\gamma+\gamma e^{-r \tau}\right)} ; \text { with } \lambda \geq \lambda^{F}(\tau) .
$$

In this region it is particularly easy to obtain the trade deficit since there is no production of traded goods:

$$
T D=(1-\gamma) E=(1-\gamma) \frac{\lambda-r \tau e}{(\mu+r)\left(1-\gamma+\gamma e^{-r \tau}\right)}
$$

Again, equation (A.6) applies. Furthermore,

$$
D(\tau)=\frac{\lambda(1-\gamma)\left(1-e^{-r \tau}\right)}{r(\mu+r)\left(1-\gamma+\gamma e^{-r \tau}\right)} ; \lambda>\lambda^{F}(\tau) .
$$

It can be seen form (A.4), (A.18) and (A.11) that $p_{N}>p_{N}^{S(0)}$ in the three regions, which implies real exchange rate appreciation for $t \in[0, \tau)$. Moreover, notice that this result is independent of $\delta$. Then, from equations (A.5), (A.6), (A.9) and (A.12) it is easy to see that trade deficits and current account deficits are monotonically increasing with respect to $\lambda$ and decreasing with respect to $\tau$ (it has to always be taken into account the restrictions on $\lambda$ in each region). Since $C_{t}$ is constant and $Q_{t}$ is continuous (due to the continuity of $K_{t}$ which is produced using nontraded goods), these deficits will continue for a while after $\tau$. Finally, it is also easy to check in equations (A.7), (A.10) and (A.13) that $D(t)$ is monotonically increasing in both $\lambda$ and $\tau$. 
Lemma 8 If there is any reduction in the capital stock (either due to a fall in its value below zero, or to borrowing constraints), it takes place at time zero (when the new productivity path is realized).

Proof. First notice that the same arguments in Claim 1 of Lemma 8 apply to the case with borrowing constraints; i.e., no capital reduction would be carried out to the point to giving rise to an interval with positive cash flow, and since at the minimum of $K(t)$, cash flow is maximum, then if at any point in the interval $[0, \tau)$ there is a capital reduction, at no point in that interval there can be a positive cash flow. Now notice that capital reductions, if any, would take place before any interval with losses is reached (it makes no sense to accumulate losses from a capital that is never going to yield a positive cash flow before you dispose of it). Now, to see that this capital reduction -if any- would take place at $t=0$, assume that a capital reduction occurs at $t^{\prime}>0$. This implies $p_{N}$ will fall at $t^{\prime}$ (due to lower demand for maintenance services). Hence cash flow will increase at $t^{\prime}$. But since cash flow does never reach positive values, we conclude it was negative before $t^{\prime}$. This contradicts that all capital reductions are done before losses. Therefore capital reductions -if any- take place at $t=0$

Lemma 9 For any borrowing constraint parameter, anticipated positive productivity shocks give rise to paths where $K(t)$ and $p_{N}(t)$ are constant for $t \in[0, \tau)$.

Proof. First notice that the same arguments in Claim 2 of Lemma 8 apply to the case with borrowing constraints: i.e., $I=0$ for $t \in[0, \tau)$. And Lemma 9 implies that all capacity reduction takes place at $t=0$. Hence the capital stock remains constant for the whole interval. This implies $L_{M}$ is constant. Since $Q_{N}$, and $E$ are also constant, the price that clears the nontraded good market is constant

Lemma 10 If the borrowing constraint (21) is satisfied at $\tau$, then it is satisfied at any $t \in[0, \tau)$.

Proof. We will show that if the borrowing constraint is not binding at $\tau$ for a given capital stock $K^{\prime}$, then it is not binding at any $t<\tau$ for that stock $K^{\prime}$. Let us assume that the constraint is binding at $t^{\prime}<\tau$ but it is not at $\tau$. Taking into account Lemma 10, binding borrowing constraints at time $t^{\prime}$ implies:

$$
c p_{K}\left(t^{\prime}\right)+\left(1-\mu p_{N}\right) \frac{e^{r t^{\prime}}-1}{r}<0 .
$$


Substituting $p_{K}$ with (18), and since cash flow cannot be positive for any interval, we get:

$$
\begin{aligned}
0>\left(1-\mu p_{N}\right) \frac{(1-c)\left(1-e^{-r\left(\tau-t^{\prime}\right)}\right)}{r}+c p^{S} & +\left(1-\mu p_{N}\right) \frac{e^{r \tau}-1}{r} \\
& >c p^{S}+\left(1-\mu p_{N}\right) \frac{e^{r \tau}-1}{r} .
\end{aligned}
$$

Which contradicts the hypothesis that the constraint is not binding at $\tau$, as we wanted to show

\section{Proof of Proposition 3}

Consider the frontier between Region I' and Region II'. Substituting with (19') and $K(0)=K_{0}=(1-\gamma) /(\mu+\gamma r)$ into system (20), and solving for $\lambda$, we obtain the following expression which defines $\lambda^{P}(c, \tau)$ :

$$
\lambda=1+\frac{r(\mu+r)\left(1-\gamma+\gamma e^{-r \tau}\right)\left(c+e^{r \tau}-1\right)}{\mu\left(1-e^{-r \tau}\right)(\mu+\gamma r)} \equiv \lambda^{P}(c, \tau) .
$$

Consider now the frontier between Region II' and Region III'. Taking $K(0)=0$ as well as the borrowing constraint (21') with equality into (20), and solving for $\lambda$ we obtain the following expression that defines $\lambda^{F}(c, \tau)$ :

$$
\lambda=\left[1-\gamma\left(1-e^{-r \tau}\right)\right] \frac{r c-(\mu+r)\left(1-e^{r \tau}\right)}{\gamma \mu\left(1-e^{-r \tau}\right)} \equiv \lambda^{F}(c, \tau) .
$$

Notice that $\lambda^{P}(1, \tau)=\lambda^{P}(\tau), \lambda^{F}(1, \tau)=\lambda^{F}(\tau)$, and that for $c<1$ and any $t$, we have $\lambda^{P}(c, \tau)<\lambda^{P}(\tau)$, and $\lambda^{F}(c, \tau)<\lambda^{F}(\tau)$. Moreover, since $\lambda^{P}(\tau)<\lambda^{F}(\tau)$, we always have $\lambda^{P}(c, \tau)<\lambda^{F}(\tau)$ as well. Therefore $\Omega$ is not empty for any $0 \leq c<1$; and, indeed, it contains Region II.

Let us now check that for shocks in $\Omega$, the stock of capital in the case of borrowing constraints is reduced more than with $c=1$. The set $\Omega$ can be partioned into three subsets: $A=\left\{(\tau, \lambda) \in \Re_{+}^{2}: \lambda>\lambda^{P}(c, \tau)\right.$ and $\left.\lambda \leq \lambda^{P}(\tau)\right\}$, $B=\left\{(\tau, \lambda) \in \Re_{+}^{2}: \lambda \geq \lambda^{F}(c, \tau)\right.$ and $\left.\lambda<\lambda^{F}(\tau)\right\}$, and $C=\left\{(\tau, \lambda) \in \Re_{+}^{2}: \lambda>\right.$ $\lambda^{P}(\tau)$ and $\left.\lambda<\lambda^{F}(c, \tau)\right\} ; \Omega=A \cup B \cup C$. For shocks in $A$, borrowing constraints force some disposal of capital, as opposed to case without these constraints in which the same shocks would imply $K(0)=K_{0}$. Second, shocks in Region III' but not in Region III define the set $B$. These shocks do bring the capital stock to zero in case of borrowing constraints, but do not in the efficient equilibrium. Third, for shocks in the set $C$ we have $0<K(0)<K_{0}$. Using (19') and (20) 
we get $K(0)$ as a function of the shock parameters and the level of borrowing constraints:

$$
K(0)=\frac{\left[\left(e^{r \tau}-1\right)(\mu+r)+r c\right]\left(1-\gamma+\gamma e^{-r \tau}\right)-\gamma \lambda \mu\left(1-e^{-r \tau}\right)}{\mu\left[(\mu+r)\left(e^{r \tau}-1\right)+r c+\gamma r(1-c)\left(1-e^{-r \tau}\right)\right]} .
$$

Notice that $K(0)$ is a decreasing function of $c$. Therefore, for any $(\tau, \lambda) \in C$, the stock of capital will be reduced more in the case of borrowing constraints than in the efficient equilibrium. Finally, notice that for any shock not belonging to any of these three sets, we would have either $K(0)=K_{0}$ or $K(0)=0$, both in the credit constrained path and in the efficient path. Hence all shocks in $\Omega$, and

only these shocks, force the capital stock to be reduced more than in the case of $c=1$.

Finally, note that since for all shocks in $\Omega$ the borrowing constraint is binding; the capital that is being spoiled has a strictly positive value. Since this is a representative agent model, this implies that the equilibrium path is inefficient

\section{Proof of Proposition 4}

In Region II' the constraint (21') is binding and can be used to substitute in system (20) to solve for $E$. Then, substituting in (12') we get:

$$
T D=\frac{\left[\left(e^{r \tau}-1\right)(\mu+r)+r c\right](\lambda \mu-\mu-\gamma r)-\gamma r c \lambda \mu}{\mu(\mu+r) e^{r \tau}\left[(\mu+r)\left(e^{r \tau}-1\right)+r c+\gamma r(1-c)\left(1-e^{-r \tau}\right)\right]}
$$

Now consider each of the subsets of $\Omega$ defined in the proof of Proposition 3 . For shocks in the subset $A$, we have to compare -for the particular combinations $(\tau, \lambda)$ belonging to the subset and assuming $c<1$ - equation (A.19) with equation (A.5). For shocks in the subset $B$, we have $K(0)=0$ and therefore the trade deficit with borrowing constraints is given by equation (A.12), which has to be compared with that given by equation (A.9). And for shocks in the subset $C$, we have to compare equation (A.19) with equation (A.9). It is easy to check in all these comparisons that the deficit is larger with borrowing constraints. On the other hand, it is clear that external debt will be higher in this borrowing constrained equilibrium, since trade deficit -and therefore the current account deficit- is higher at any point of time.

Now, exchange rate appreciation will be lower with borrowing constraints if the rise in $p_{N}$ is smaller. For shocks in Region II' the constraint (21') is binding and determines $p_{N}$ :

$$
p_{N}=\frac{(\mu+r)\left(e^{r \tau}-1\right)+r c}{\mu(\mu+r)\left(e^{r \tau}-1\right)} .
$$


Let us consider again each of the subsets of $\Omega$. For shocks in the subset $A$, we have to compare equation (A.20) with equation (A.4). For shocks in the subset $B$, we have $K(0)=0$, and therefore $p_{N}$ with borrowing constraints is given by equation (A.11), which has to be compared with that given by equation (A.8). And for shocks in the subset $C$, we have to compare equation (A.20) with equation (A.8). It is easy to check in all these comparisons that the appreciation is smaller with borrowing constraints

\section{Proof of Proposition 5}

When the consumption of both goods is taxed, the system (20) takes the following form:

$$
\begin{aligned}
E & =r p_{K}(0) K(0)+p_{N}\left(1-e^{-r \tau}\right)+\frac{\lambda}{\mu+r} e^{-r \tau}+\frac{\theta E}{1+\theta}\left(1-e^{-r \tau}\right) \\
1 & =\mu K(0)+\frac{\gamma E}{p_{N}(1+\theta)} \\
p_{K}(0) & =\left[\frac{1-\mu p_{N}}{r}\right]\left(1-e^{-r \tau}\right)+\frac{e^{-r \tau}}{\mu+r} .
\end{aligned}
$$

Since we consider only Region II', (21') is binding. This equation, together with the new version of system (20) will allow us to solve for the main variables. On the other hand, the indirect utility function is now:

$$
\begin{aligned}
U= & \left(\frac{1}{r}\right)[\log (E)+(1-\gamma) \log (1-\gamma)+\gamma \log (\gamma)]-\left(\frac{1-e^{-r \tau}}{r}\right) \log (1+\theta)- \\
& -\frac{\gamma}{r}\left[\left(1-e^{-r \tau}\right) \log \left(p_{N}\right)+e^{-r \tau} \log \left(p_{N}^{S}\right)\right] .
\end{aligned}
$$

Substituting for $E$ and $p_{N}$ in this equation, and taking derivatives, we obtain:

$$
\lim _{\theta \rightarrow 0} \frac{\partial U}{\partial \theta}=\frac{\gamma r(1-c)\left(1-e^{-r \tau}\right) e^{-r \tau}}{\gamma r(1-c)\left(1-e^{-r \tau}\right)+\left(e^{r \tau}-1\right)(\mu+r)+r c}>0 .
$$

Hence a -small enough- consumption tax would increase welfare. Finally, substituting $E$ in (12') we have:

$$
T D=\frac{\left[\left(e^{r \tau}-1\right)(\mu+r)+(1-\gamma) r c\right]\left[\mu+r+\mu(\lambda-1) e^{-r \tau}\right]}{\mu(\mu+r)\left[\gamma r\left(1-e^{-r \tau}\right)(1-c)+\left(1+\theta e^{-r \tau}\right)\left[(\mu+r)\left(e^{r \tau}-1\right)+r c\right]\right]}-\frac{1}{\mu} .
$$

Clearly, raising $\theta$ would reduce the trade deficit

\section{Proof of Proposition 6}


When only consumption of the nontraded goods is taxed, the system (20) takes the following form:

$$
\begin{aligned}
E & =r p_{K}(0) K(0)+p_{N}\left(1-e^{-r \tau}\right)+\frac{\lambda}{\mu+r} e^{-r \tau}+\frac{\gamma \theta_{N} E}{1+\theta_{N}}\left(1-e^{-r \tau}\right) ; \\
1 & =\mu K(0)+\frac{\gamma E}{p_{N}\left(1+\theta_{N}\right)} ; \\
p_{K}(0) & =\left[\frac{1-\mu p_{N}}{r}\right]\left(1-e^{-r \tau}\right)+\frac{e^{-r \tau}}{\mu+r} .
\end{aligned}
$$

And the indirect utility function is now:

$$
\begin{aligned}
U=\frac{1}{r}[\log (E)+(1-\gamma) & \log (1-\gamma)+\gamma \log (\gamma)] \\
& -\frac{\gamma}{r}\left[\left(1-e^{-r \tau}\right) \log \left[p_{N}\left(1+\theta_{N}\right)\right]+e^{-r \tau} \log \left(p_{N}^{S}\right)\right]
\end{aligned}
$$

Using the previous system to substitute $E$ and $p_{N}$ in this function, and maximizing subject to $\left(19^{\prime}\right)$, we obtain the optimal levels of $\theta_{N}$ for every shock in $\Omega$ :

$$
\begin{aligned}
& =\frac{(\mu+\gamma r)\left(1-e^{-r \tau}\right) \mu(\lambda-1)}{(\mu+r)\left(1-\gamma+\gamma e^{-r \tau}\right)\left[\left(e^{r \tau}-1\right)(\mu+r)+r c\right]}-\frac{r\left(c+e^{r \tau}-1\right)}{\left(e^{r \tau}-1\right)(\mu+r)+r c} \\
\theta_{N}^{*} & \quad \text { if }(\tau, \lambda) \in A . \\
& =\frac{r(1-c)}{\left(e^{r \tau}-1\right)(\mu+r)+r c} \quad \text { if }(\tau, \lambda) \in(B \cup C) .
\end{aligned}
$$

For shocks in the subset $A,\left(19^{\prime}\right)$ is satisfied with $K(0)=K_{0}$, while for shocks in $B \cup C$, the borrowing constraint is binding. Taking this into account to substitute in (A.25), it can be checked that, for any shock in $\Omega$, this tax implies a relative price for consumption, $p_{N}^{\prime}$, equal to the value of $p_{N}$ in the efficient equilibrium, as well as the same expenditure and capital stock. Hence $\theta_{N}^{*}$ brings the economy back to the efficient path 
FIGURE 1

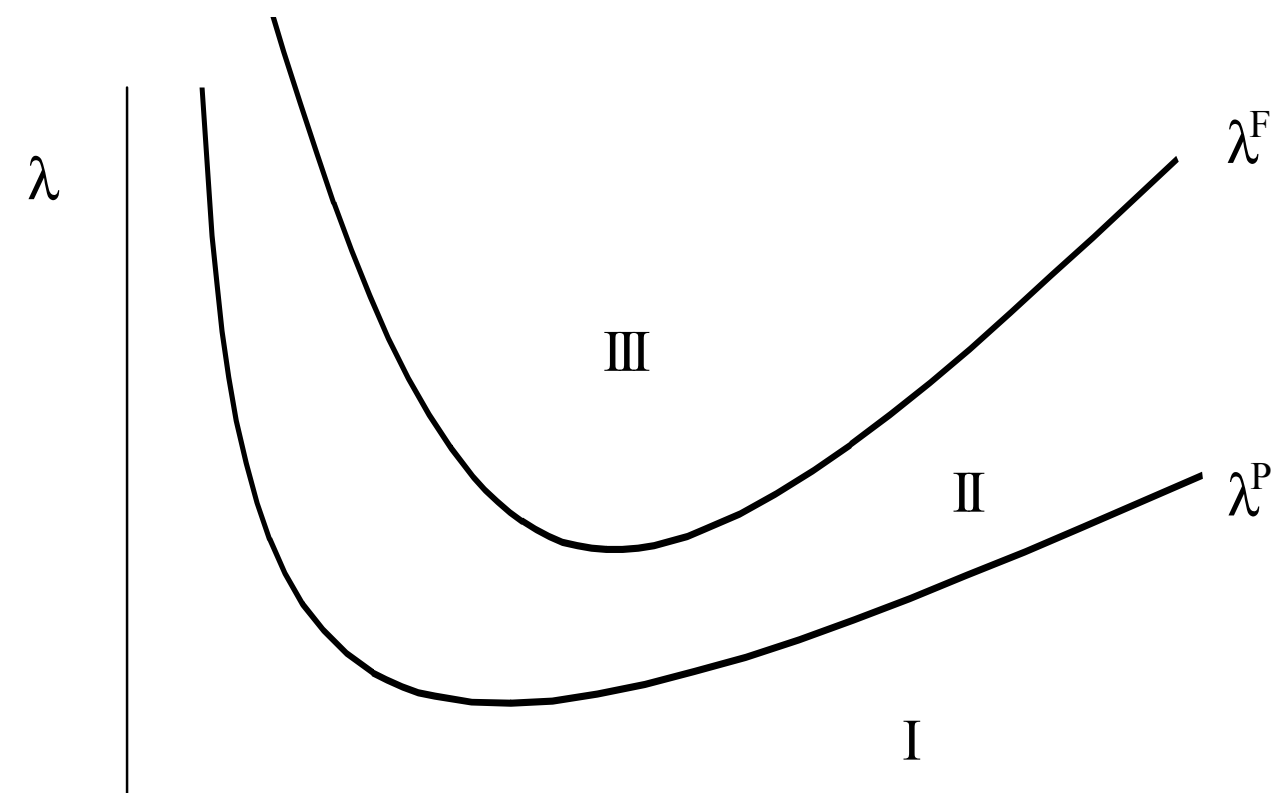


FIGURE 2

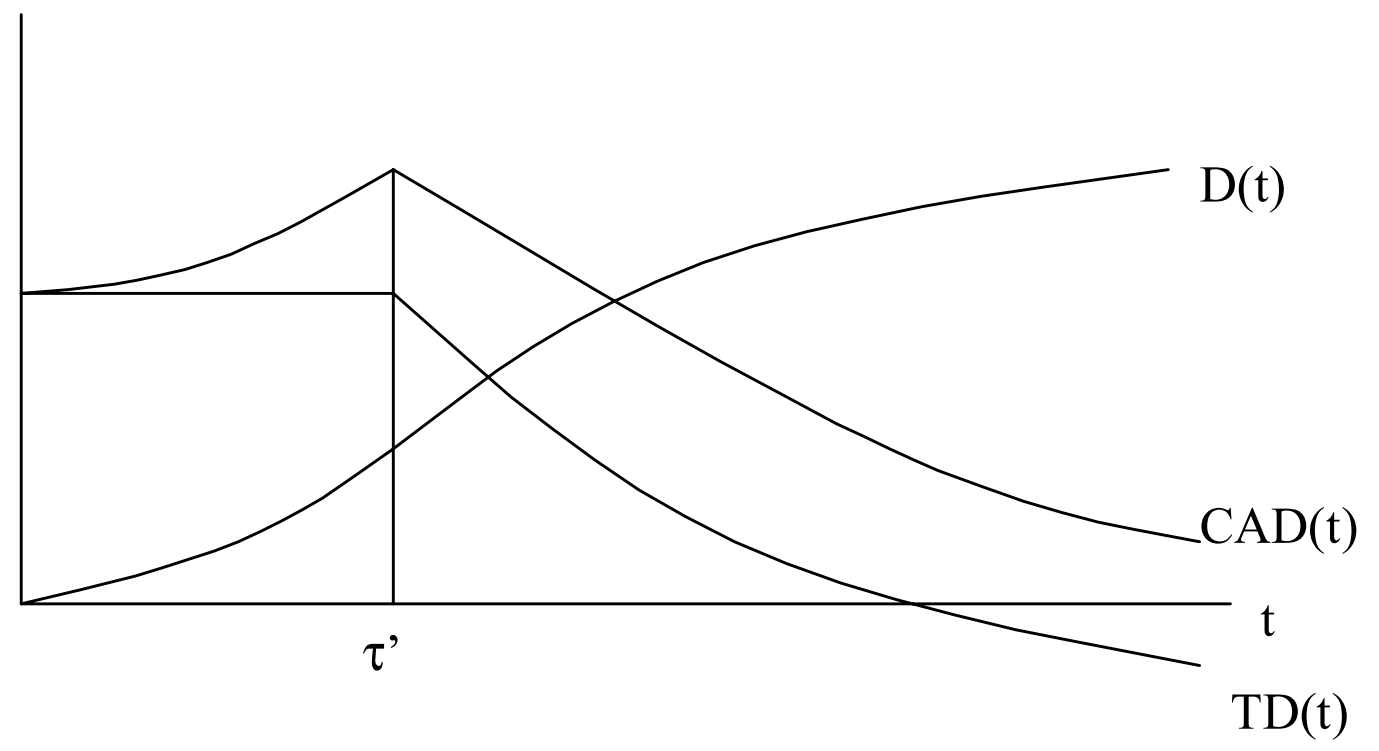


FIGURE 3

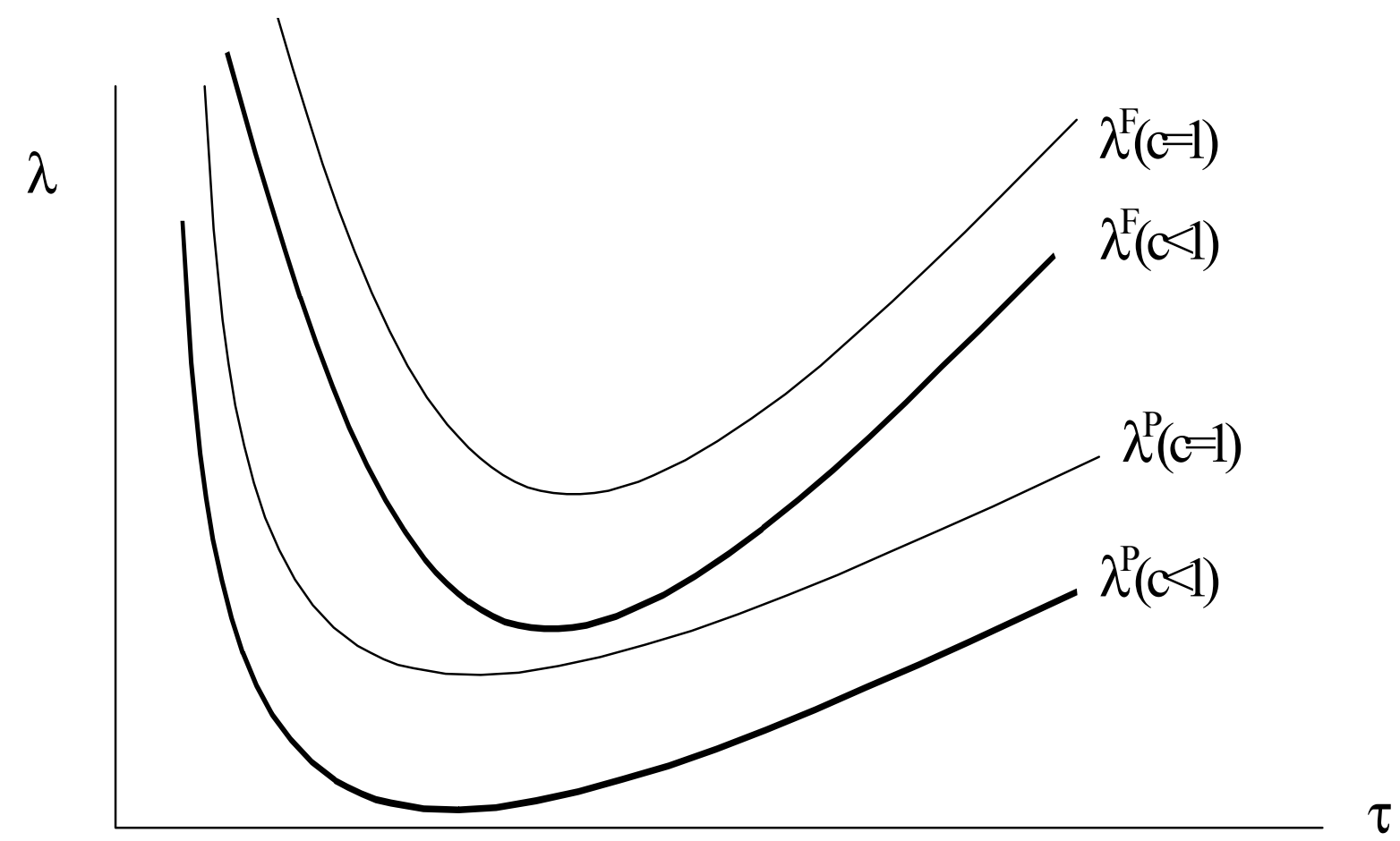


FIGURE 4

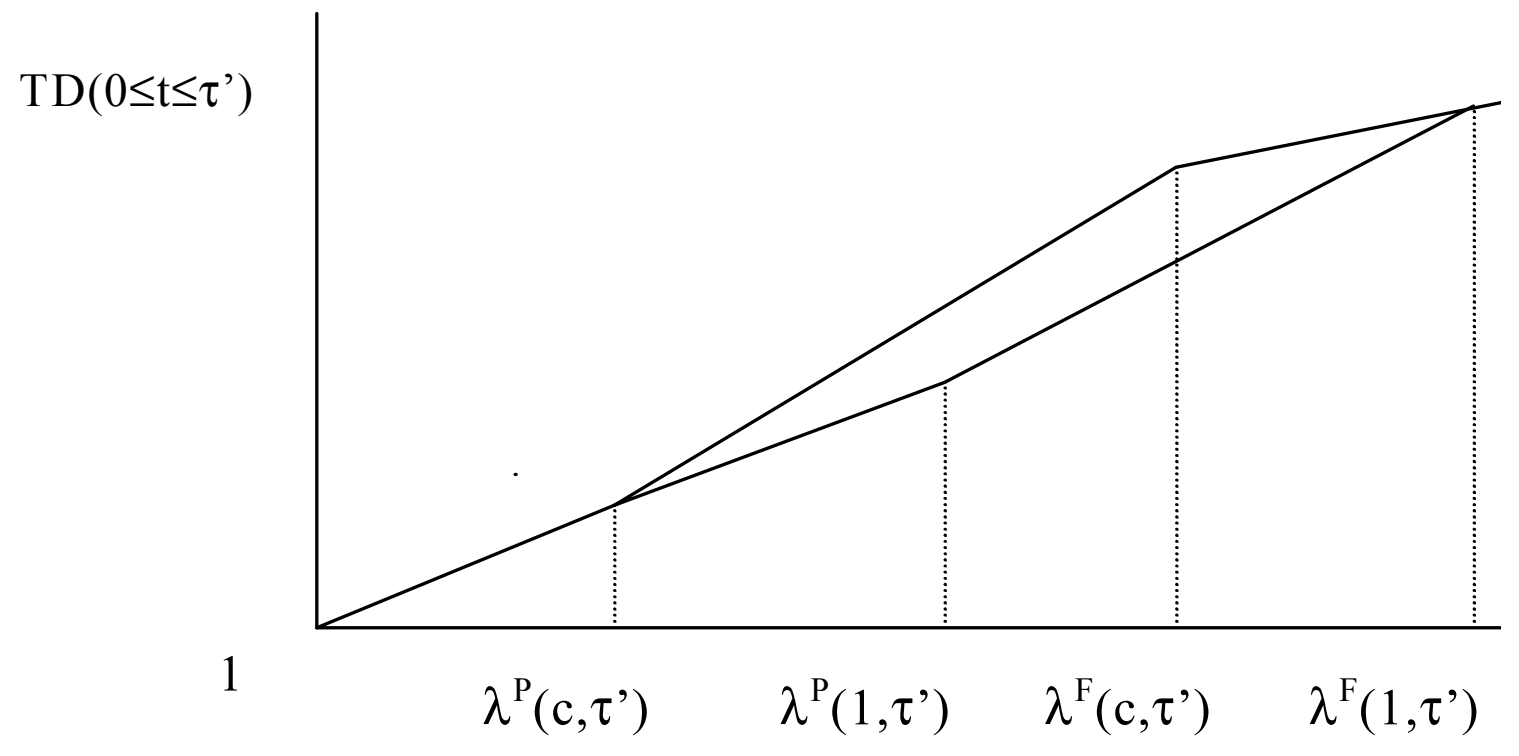

